Dovey, K. Pike, L. \& Woodcock, I. (2016)

'Incremental Urban Intensification', Urban Policy and Research, Online Publication: DOI: 10.1080/08111146.2016.1252324

\title{
INCREMENTAL URBAN INTENSIFICATION: Transit-Oriented Re-Development of Small-Lot Corridors
}

\author{
Kim Dovey , Lucinda Pike and lan Woodcock
}

\begin{abstract}
The imperative to transform car-dependent cities for a low-carbon future requires that we engage with the challenge of increasing densities along existing road-based transit corridors - within the constraints of existing morphologies. Such corridors are often lined with small lots that are valued for their functional mix and urban character. This paper explores the degree to which small and narrow lots constrain urban intensification through a study of tram corridors in Melbourne. We examine the impact of site area, shape and access conditions as constraints on re-development and increased density. We find that small and narrow lots have not prevented intensification that is substantial in its accumulated effect and contributes more to urban character than large lot re-development. The paper discusses the relations of urban morphology to questions of car-dependency, development capacity and resident resistance.
\end{abstract}

Keywords: incremental, intensification, compact city, transit-oriented, morphology, density, lot-size, urban character

\section{INTRODUCTION}

Intensified urban development with walkable access to mass transit is now well recognized as a key challenge for urban development in an era of climate change and the imperative for a low-carbon city (Newman et al. 2009). The problem for highly car-dependent cities is partly one of adapting the existing morphology for intensification around existing transit lines and nodes. Such existing neighbourhoods are often small-lot subdivisions that are highly valued by local residents for their diversity, low density and neighbourhood character - there is often substantial resident resistance to transformational change. This paper engages with the question of the degree to which small-lot subdivisions constrain or enable urban intensification. While the focus is on one city, the lessons are likely to apply in different degrees to any transit corridor characterized by low-density small-lot morphologies. The key question here is the degree of urban intensification that is possible while maintaining the diverse morphology of the small-lot subdivision.

While incremental intensification is a practice as old as cities there is remarkably little research literature investigating the ways in which morphology and lot size constrain or enable it. The idea of small-grain development was integral to the seminal work of Jacobs (1961) where it was part of the way cities sustain diversity. Small-lot subdivisions produce diversified land ownership, often geared to a valuable mix of functions and building types. Since properties are separately developed, over time the city acquires a mix of old and new buildings with a range of different rental values and levels of affordability. For Jacobs this diversity is linked to streetlife vitality, walkability and economic productivity. The values of intensified small-grain mixed-use development have become an integral part of recent urban design movements including New Urbanism, transit-oriented development and main street revitalization programs (Duany and Talen 2002; Newman et al. 2009; Curtis et al. 2009; Dunham-Jones and Williamson 2011; Dittmar and Ohland 2004). In many contexts the architectural and functional mix enabled and produced by the small-grain morphology has become linked to the emergence of place identity and urban character (Dovey 2013). The importance of urban design that encourages diversity and mixed use has come to the fore with the growing attention to walkability (Cervero and Kockelman 1997; Talen 2006; Lo 2009; Forsyth 2015). 
The 'lot' or 'plot' (also known by the terms land 'parcel' or 'cadastre') has long been considered a primary element for any kind of morphological analysis from the early work of Conzen (1960) through that of (Moudon 1986) to recent works of Marshall (2009: 67), Pont and Haupt (2010: 101) and many others. The lot plays a key role in the morphogenesis of the city as the primary territory for market transaction and construction. The small-lot morphology enables an increased level of adaptability of function that can also be linked to urban vitality (March et al. 2012). It is also a truism of urban design thinking that small lots - for better or worse - represent a general constraint on urban transformation. Major projects require large sites while small lots with multiple owners are inherently difficult to amalgamate. Lot size thus affects the rate at which a city develops, yet small lots can also allow high levels of incremental change since control is distributed. In her seminal study of San Francisco, Moudon mapped a high level of adaptability of small lot subdivisions over nearly a century of change as buildings incrementally densified from 1-3 storeys to 6-8 storeys with few site amalgamations, and diversified from primarily single family housing to mixed-use (Moudon 1986: 17-18). Like Jacobs, she also argued the normative case for small-lot subdivision in terms of distributed control and neighbourhood diversity: "A neighbourhood of small lots belongs to many different and small groups. It also affects variety in building design... The smaller the increment of land ownership, the more variety created in the environment" (Moudon 1986: 141). In another of the earlier studies Myers and Baird (1978) put the case for incremental intensification or 'infill' as it was then known and their work in Vancouver suggested that small-lot sizes presented a significant constraint. Such a view has been echoed since by Tabuchi (1996), Mejias and Deakin (2005), Gao and Asami (2007) and Glackin and Trubka (2013). Mejias and Deakin (2005) found that smaller lots are generally seen as a drawback by developers and require a higher level of design creativity. Tabuchi (1996) also found that larger lots bring a higher price per square metre. In the Japanese context Gao and Assami (2007) found that lot size and shape were more important factors for redevelopment than the restrictions of FAR (Plot Ratio); a minimum financially viable lot-size was found to be about 100 square metres. The minimum street frontage (often about 6 metres) emerges as a key variable in several of these studies (Gao and Assami 2007; Colwell and Scheu 1989; Glackin and Trubka 2013) and is often connected to the issue of car access, particularly in the North American context (Tumlin and Millard Ball 2003).

The imperatives for transit-oriented development and urban intensification of car-dependent cities have increased in recent decades with the growing crisis of climate change together with the demand for transport efficiency and a more walkable healthy city. Since many existing transit corridors have developed with a small-lot morphology, the question of how much and in what ways small-lot morphologies constrain re-development becomes one of wider relevance. Most existing research has explored the broader constraints of lot-size on intensification; in this study we also seek to open up a set of further questions within an approach derived from assemblage theory (Dovey 2016). How does the issue of lot-size play out within the complex set of urban forces including market demand, resident resistance, car-dependency and design quality? What is the distinction between urban 'intensification' and simple 'densification', and how is this impacted by lot size? How is development 'capacity' mediated by both the micro-morphology of the city and resident perceptions of over-development? An earlier study in Melbourne found that resident opposition to intensified redevelopment on tram corridors increases sharply above about four storeys unless there is a significant step-back (Woodcock et al. 2012). We will argue that while small lot-size offers some constraint on density, it is also productive of intensive streetlife and urban character. Incremental intensification is a middle road for transformational change where urban character becomes intensified rather than damaged in the move towards a more walkable compact city and a low-carbon future.

\section{MELBOURNE}

Melbourne is a key test-site for such issues, regularly listed as a 'most livable' city yet with low densities and entrenched car-dependency. The urban policy framework has long called for consolidation within existing activity centres and along transit corridors but change has been difficult in the face of community resistance to what is seen as a threat to the valued character of suburban life (Lewis 2000; Buxton and Tieman 2005; Dovey et al. 2009). There has been very substantial debate about urban consolidation in Australian cities yet most of it is played out through a metropolitan discourse on policy and ideology, with 
little attention to the particularities of urban morphology. The middle-ring suburbs between about 5-15 $\mathrm{km}$ from the central city have been identified as the crucial challenge and opportunity for transformation to a low-carbon city (Adams 2009; Newton et al. 2012) - sites have long been settled at low densities with little redevelopment and low population growth. While this kind of development has long been called 'infill' (Myers and Baird 1978; Newton and Glashin 2014) this is an ambiguous term that can mean very different things at different scales: from brownfield developments within the existing city to developing vacant lots in a particular streetscape. The redevelopment we are studying often entails replacement of 12 storey shops or housing with a 4-8 storey mix of housing with shops at ground level; there is no gap that is being filled.

Melbourne has a very extensive tram network mostly built in the period between 1885-1940. The routes are lined with small-lot subdivisions incorporating housing, retail and industry with buildings rarely exceeding three storeys. While trams are generally crowded they are slowed by road congestion and frequency is often low. Many routes are not operating at capacity creating scope for corridor intensification. There are significant corridor segments of mixed landuse and in some cases vacancies are high. Many of the streetscapes are vibrant and walkable with good access to a residential catchment. These conditions suggest there is much potential to both intensify and improve the amenity of such tram corridors (Newton et al. 2012).

Compact city policies apply at both state and local governance levels, yet corridor intensification is frequently a site of resistance and tension (Lewis 2000, Woodcock et al. 2012). Resident groups have bitterly opposed developments that they see as too large and out of character with the context. At the same time, developers have argued for larger lot-sizes and greater height limits as a way to improve the viability of corridor intensification. Heritage and other development overlays often restrict the capacity for site amalgamation and intensification generally. Local councils are elected by residents and are often reluctant to support site amalgamation or increased height limits. Car parking is another contentious issue for corridor intensification. With increasing densities, existing residents are frequently concerned about the congestion of on-street parking and increased local area traffic. Residents often resist efforts by developers to reduce the amount of car parking included in developments, and apartments without a car park can be more difficult to finance and sell. In this study area at least one on-site car park must be provided per dwelling although exemptions are sometimes approved.

In the study entitled 'Transforming Australian Cities' Adams (2009) proposed that intensification of roadbased mass transit corridors represents the major opportunity to absorb substantial new development while also protecting the character of existing suburbs. Adams called for as-of-right development from 48 storeys for sites with frontages to the transit routes. Sites covered by heritage overlays, with less than 6 metres frontage, or lacking rear lane access were excluded from consideration on the basis that they did not offer potential for intensification. This strategy left the vast majority of existing suburban development within the walkable residential catchments behind the strip frontage largely untouched. A related study (Woodcock et al. 2010) incorporating rail and bus corridors found that the existing morphology held the capacity to accommodate projected population growth with modest intensification at 4-5 storeys.

\section{THE STUDY}

The tram network in metropolitan Melbourne comprises a total of $242 \mathrm{~km}$ of tram routes - mostly dating from the late 19th and early 20th century, this is one of the most extensive light rail systems in any city. The structure of the system is that of a network in the central city becoming radial in the inner and middle suburbs. Our sample is drawn from a $5 \times 5 \mathrm{~km}$ frame located in the middle-ring suburbs where significant potential for intensified development can be found (Figure 1). It extends from about 4-10 kilometres from the city centre, largely outside the heritage areas of the inner-city yet well within metropolitan boundaries. This 25 square kilometre frame contains a series of six tram corridors totaling $29 \mathrm{~km}$ that were analysed for this study. All lots located directly adjacent to the tram routes were mapped according to size, shape and level of access. In total this comprised 3867 individual lots covering an area of 192 hectares along the six tram corridors. In addition we identified all such lots that have been re-developed over the period of 2000-2014 (Figure 1) and analysed them according to lot size, shape and access as well as the density of redevelopment. 

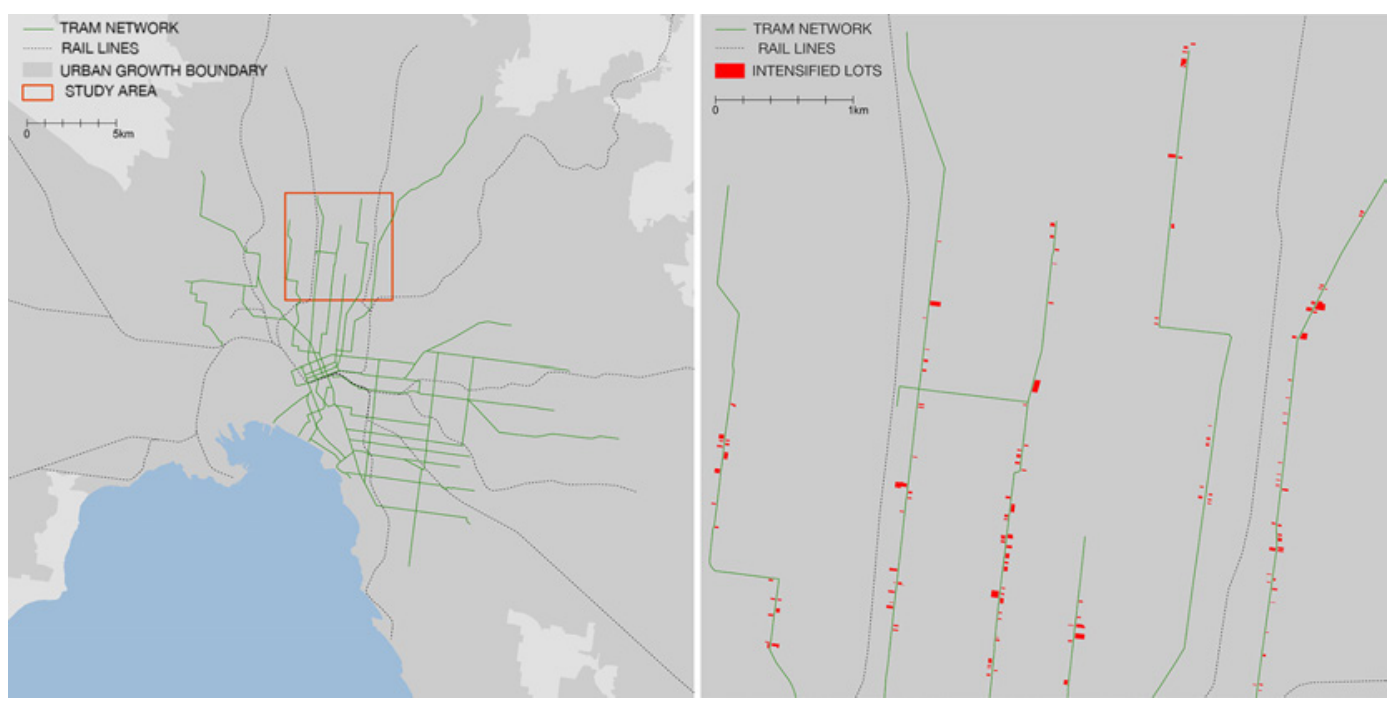

Figure 1: Metropolitan Melbourne and Study Area showing intensified lots

The range of existing streetscapes is illustrated in figure 2 - from suburban (2A) to industrial $(2 \mathrm{~B}, 2 \mathrm{C})$ and retail $(2 \mathrm{D}, 2 \mathrm{E})$ with retail strips having the smallest grain and the most active public interface. While some strips have development constraints due to heritage (2D), many corridors are somewhat derelict (2B) and/or have very significant potential for redevelopment (2B, 2C, 2E). Figure 3 shows examples of some of the most substantial redevelopments that have taken place during our study period. They range from about four storeys (3A) to nine storeys (3B) depending on local codes and on site-by-site decisions of planning tribunals. They are at times juxtaposed against single or two-storey suburban or retail buildings (3B, 3C, 3D) or even vacant lots (3E), they are in no sense 'infill'. Some streetscapes have been largely transformed from 1-2 storeys to 3-6 storeys (3A). Projects that occur within retail strips are generally required to maintain an active retail frontage (3A, 3B) or to create one on former industrial sites (3C) but car-based frontages are not uncommon (3E). 
A

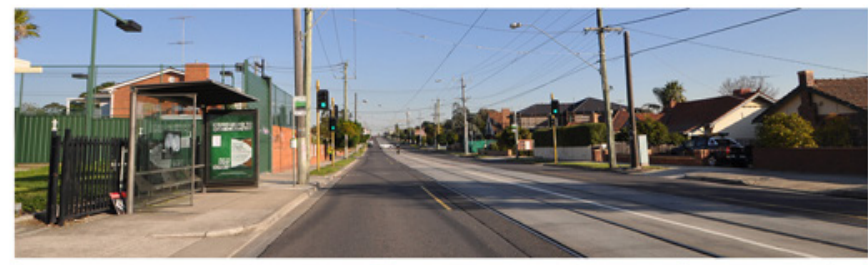

B
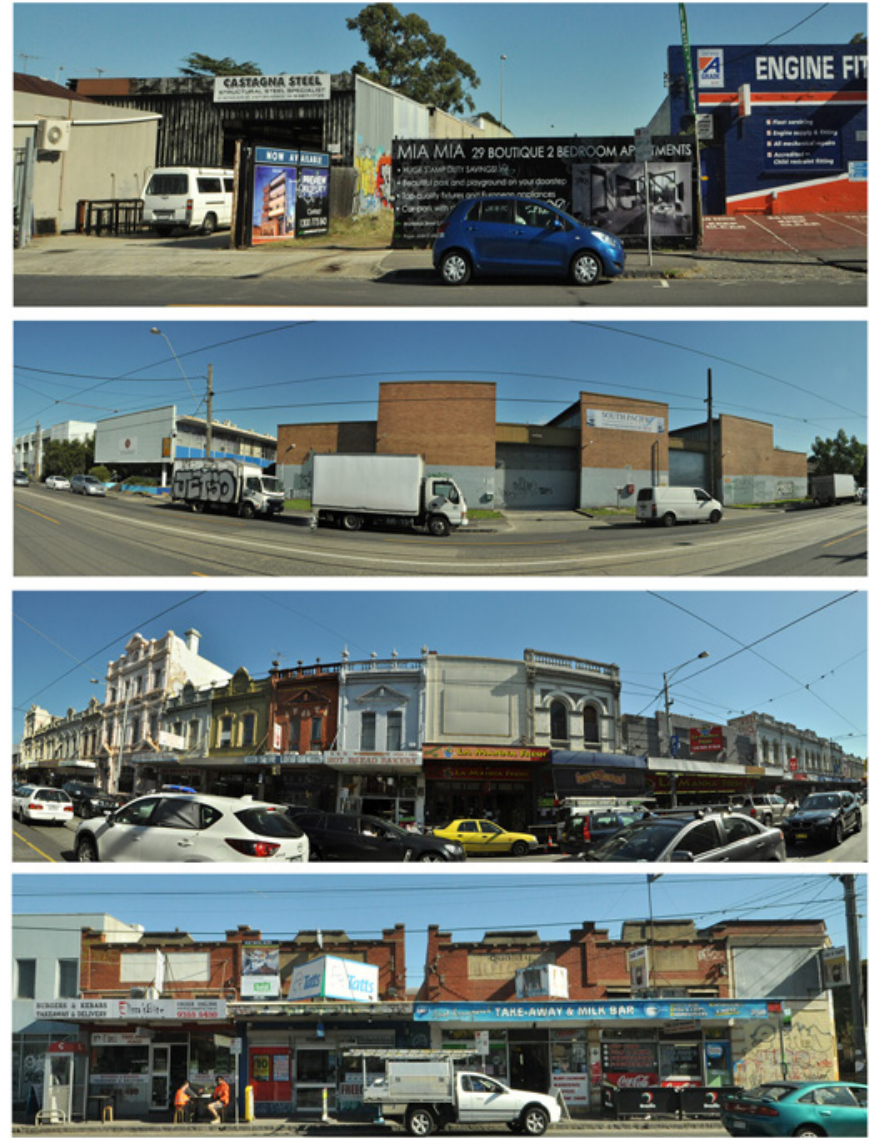

Figure 2: Existing morphologies before redevelopment 
A

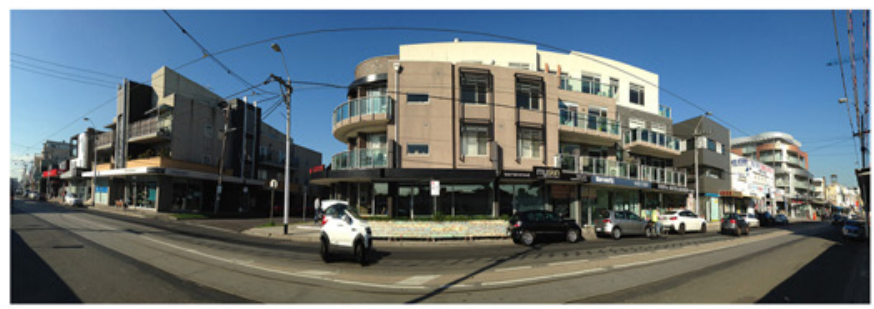

B

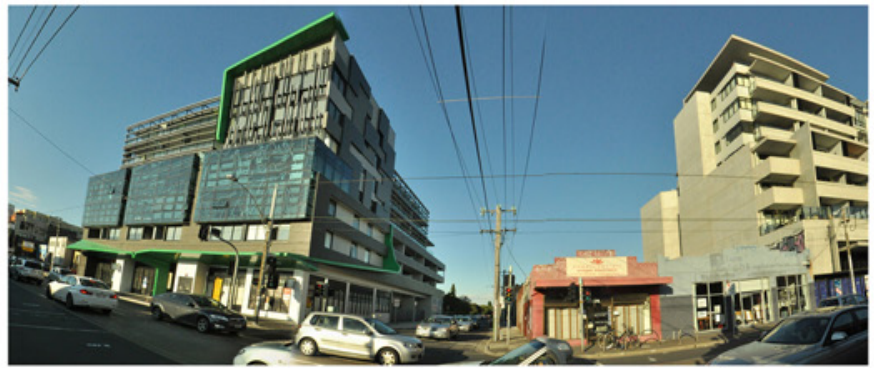

C

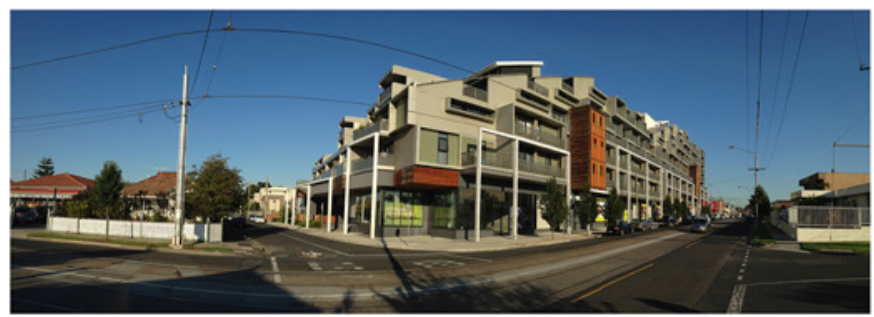

D

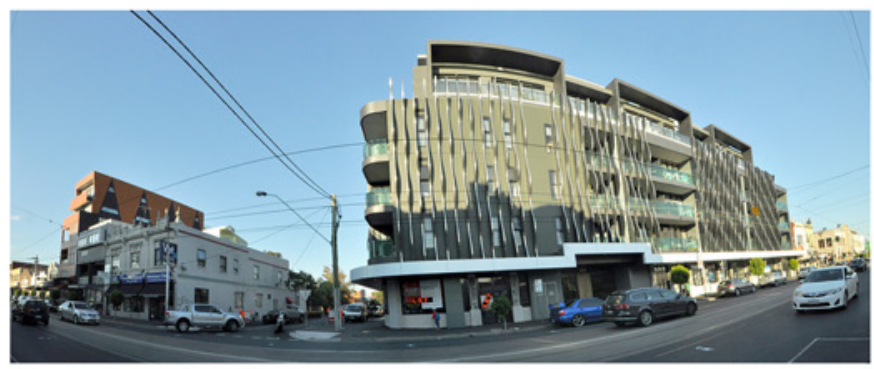

$\mathrm{E}$

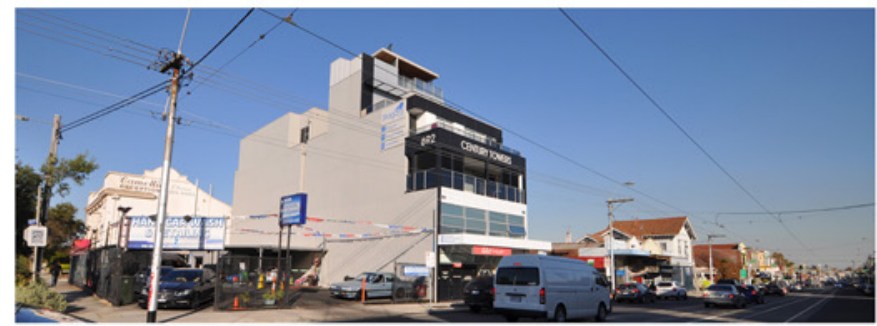

Figure 3: Recent redevelopments (2000-2014)

The three factors anticipated to be most likely to affect intensification were lot-size, lot-shape and street access. These three factors of size, shape and access were chosen due to being perceived constraints on development. Lots that are too small or narrow are frequently cited as lacking capacity to produce sufficient density or a viable project size (Tabuchi 1996; Mejias and Deakin 2005; Gao and Asami 2007; Glackin and Trubka 2013). Access is an issue because of the general requirement for off-street parking (Gao and Assami 2007; Colwell and Scheu 1989; Glackin and Trubka 2013). Under current provisions single access lots require car access from the main street frontage. The ways we have categorized them are shown in Table 1.These three typologies are designed to cover the range of lot sizes, shapes and access conditions within this case study. Lot-sizes required the largest range and were classified into five categories from Extra Small (<250 sq. metres) to Extra Large (>5000 sq. metres). Lots were also classified into three shape categories based on the ratio of width to depth: Extra Narrow, Narrow and Broad. The 'broad' category also incorporated irregular lot shapes as well as shallow lots with wide street 
frontages. Street access was classified according to Single access (single street frontage), Dual access (street plus backlane) and Corner access (two street frontages).

\begin{tabular}{|c|c|c|c|c|c|}
\hline LOT-SIZE & $\begin{array}{c}\text { X-SMALL } \\
<250 \mathrm{~m}^{2}\end{array}$ & $\begin{array}{c}\text { SMALL } \\
250-750 \mathrm{~m}^{2}\end{array}$ & $\begin{array}{c}\text { MEDIUM } \\
750-2000 \mathrm{~m}^{2}\end{array}$ & $\begin{array}{c}\text { LARGE } \\
2000-5000 \mathrm{~m}^{2}\end{array}$ & $\begin{array}{c}\text { X-LARGE } \\
>5000 \mathrm{~m}^{2}\end{array}$ \\
\hline $\begin{array}{c}\text { LOT-SHAPE } \\
\text { (width:depth) }\end{array}$ & $\begin{array}{c}\text { X-NARROW } \\
>1: 5\end{array}$ & $\begin{array}{c}\text { NARROW } \\
1: 5-1: 2\end{array}$ & $\begin{array}{c}\text { BROAD } \\
1: 2-1: 1\end{array}$ & & \\
\hline ACCESS & $\begin{array}{c}\text { SINGLE } \\
\text { (1 street) }\end{array}$ & $\begin{array}{c}\text { DUAL } \\
\text { (street + lane) }\end{array}$ & $\begin{array}{c}\text { CORNER } \\
\text { (2 streets) }\end{array}$ & & \\
\hline
\end{tabular}

Table 1: Morphological Categories

A second layer of analysis was to identify all new buildings constructed from 2000-2014 that could be considered intensification (including residential use at a rate greater than one dwelling/lot). For this sample of 156 intensified properties, additional characteristics were documented including height, interface conditions at front and rear, number of dwelling units and ground floor functions. The two measures of intensification were building height and dwellings per hectare. The classification of height here is relative to the suburban context. These tram corridors have traditionally been lined with 1-2 storey development rarely over 3 storeys. More recent developments only rarely exceed 6 storeys. In this context we classified buildings of up to 3 storeys as Low, 4-5 storeys as Medium, and 6 storeys or more as High. The collection of data on the number of dwelling units allowed for net densities of dwellings per hectare to be calculated. These measures of actual intensification are then compared to the morphological data in order to better understand how the site size, shape and access conditions enable or constrain intensification. This is an exercise in trying to understand capacities for urban change; while we have enumerated characteristics of the urban morphology, capacity for development depends on a much larger socio-spatial assemblage of actors and interests incorporating design, governance, residents and the development industry. While this study will relate to the particular local context, the method was developed to allow a detailed study of the potential for any small grain corridor intensification.
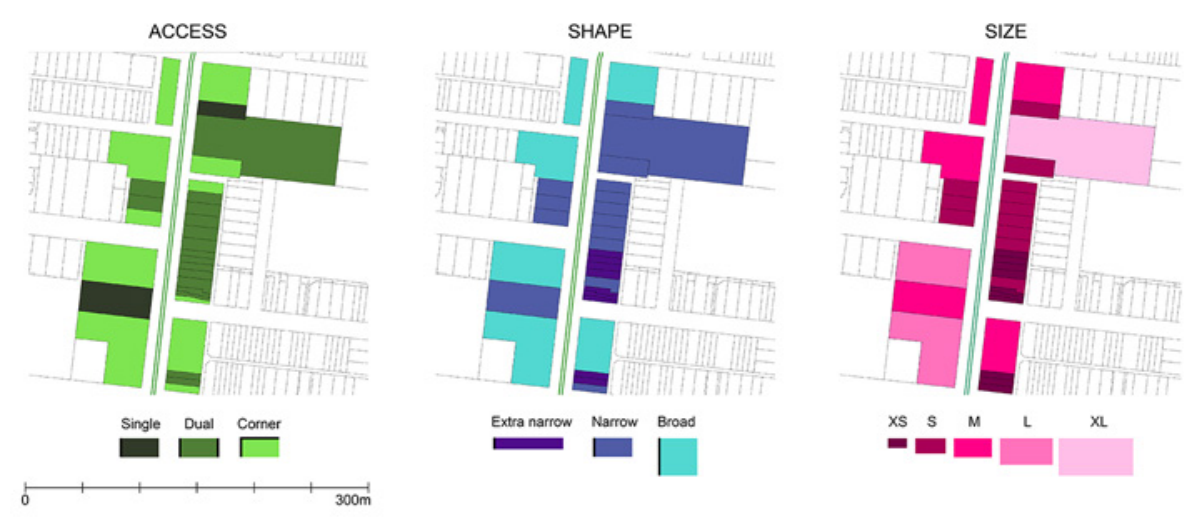

Figure 4: Sample mix of Access, Shape and Size of Lots

Figure 4 shows a sample of the mix of access types, lot shapes and sizes along a 300 metre segment of tram corridor. It shows some of the ways in which these three criteria can be identified within this particular morphology and the ways in which each individual lot has been separately categorized. In this stretch located relatively close to the city, all lot sizes, shapes and access types are represented. Other parts of the study area, located further from the city were often suburban with a greater consistency of lot size and shape. 


\section{PREVALENCE AND PREFERENCE OF LOT TYPES}

We now present the findings of this study through a distinction we want to make between the 'prevalence' of different lot types and sizes, compared to the 'preference' of developers as evident in their re-development choices. While our focus is on morphology we acknowledge that development decisions are subject to other influences especially the availability of particular lots on the market. Figure 5 is a graphic representation of the entire database developed for this study including both the existing morphology (prevalence) and the intensified parts of it (preference). Our method of analysis generates a total of 45 categories of site types - 3 shapes $\times 3$ forms of access $\times 5$ lot-sizes. The upper diagram shows a $3 \times 3$ grid where the three shape variables (broad, narrow, extra-narrow) are mapped against the three access variables (single, dual, corner). In each of these boxes we have represented the percentage of the total land area that falls into that category, then further differentiated by site size. Thus all of the existing land in the study area is represented in a single image.

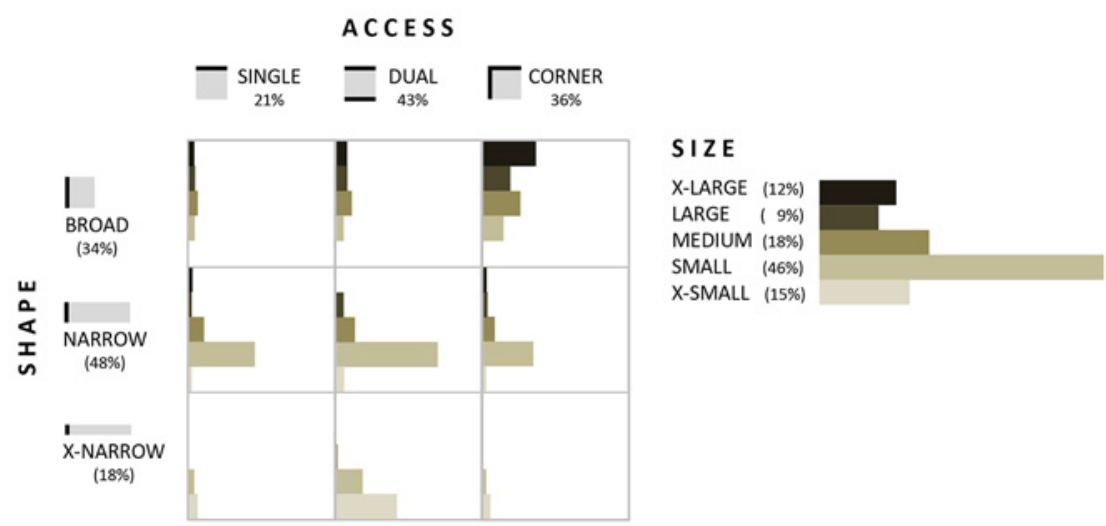

A: PREVALENCE (all lots)

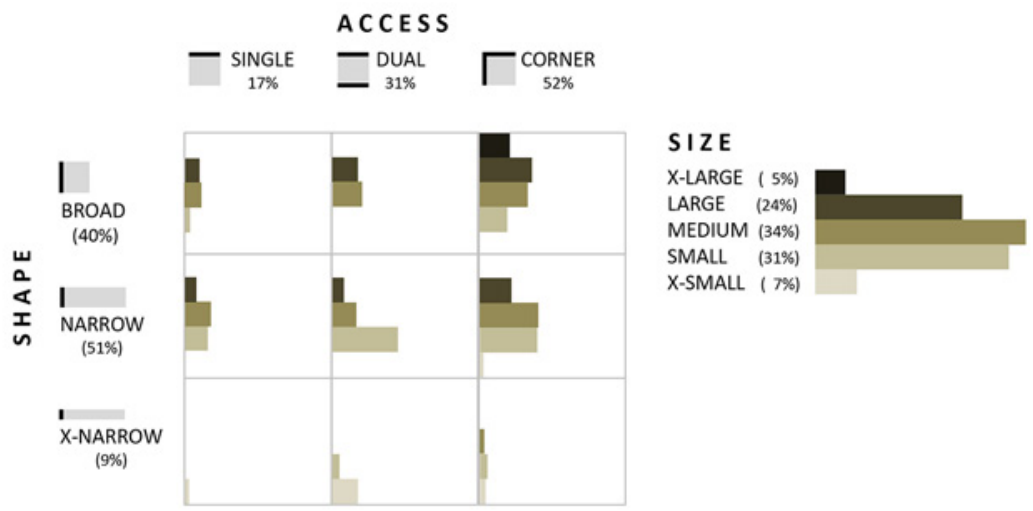

B: PREFERENCE (intensified lots)

Figure 5: Prevalence and Preference by Access, Shape and Size

First, some general observations based on the prevalences of lot size, shape and access as evident in Figure 5A. While all size categories are well represented, almost half $(46 \%)$ of the total land area falls in the small category (between 250-750 sq m). With regard to plot shape, almost half (48\%) of all land area is on sites categorized as narrow. While there are significant numbers of extra-narrow lots (with a depth over five times the frontage), they comprise only $18 \%$ of the area. Levels of access are generally mixed but again most land (79\%) has dual or corner access. Because our focus is on development capacity all measures are of total land area and not numbers of lots which would give a very different result. 
While Figure 5A shows the prevalence of different lots by land area, Figure 5B uses the same framework to show the preferences for different lot shape, size and access by showing only those lots that have been re-developed and intensified over the study period (2000-2014). Within this study area, approximately $6 \%$ of all land has been intensified (11 out of 192 hectares). Figure 5B shows that development is distributed primarily across the three middle lot-sizes comprising $89 \%$ of all re-developed land, however, there are no high concentrations on any particular lot-types. As one might expect there seems a general aversion by developers to extra-narrow and extra-small lots. The key question raised by Figure 5 is how do these preferences compare with the prevalences of the same lot types? How does the choice of re-development lot relate to the availability of those lot types? We want to call this the preference/prevalence ratio. A ratio of 1:1 would indicate that the site type is being developed in the same proportion as its prevalence, ratios greater and lesser than this would indicate a greater preference or aversion respectively. Figure 6 combines the data from figures $5 \mathrm{~A}$ and $5 \mathrm{~B}$ into a single image where the preference/prevalence ratio is represented as a level of intensity. This image can then be read as an indicator of demand as applied to the relative availability of site types. It shows that intensification of medium and large sites is occurring at well in excess of their prevalence along these corridors and suggests that lot size has a significant influence on market uptake. It also shows that small site size is neutral while extra-large and extra-small lots constrain intensification.

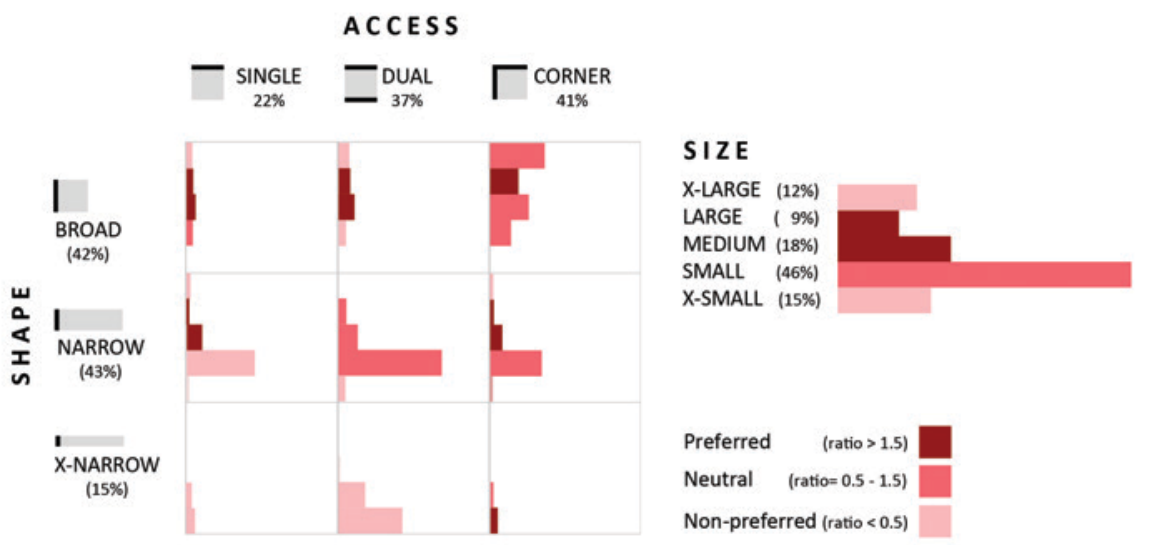

Figure 6: Preference/Prevalence Ratios by Lot Type

In making this distinction between 'prevalence' and 'preference' we also need to note that our study area extends from between 4 to 10 kilometres from the central city and that demand and land costs increase with proximity to the city; average house prices decline by about $15 \%$ across this range. The paucity of development on extra-large sites may be accounted for by the fact that such sites are more common further from the city where demand for large-scale apartment developments is lower (a condition that may change over time). As might be expected Figure 6 suggests a greater preference for broader sites and an aversion to extra-narrow (except on corners). There is no clear preference for corner lots and little aversion to single access unless they are small and narrow. Figure 6 again suggests an aversion to extrasmall and extra-large sites and a preference for small sites only where they are square or have corner access. If lots are single access then larger sizes are preferred. It is important to note that the impact of these preferences is in proportion to the total area of that lot type - a preference for a lot type that is scarce has little significance. In this regard we note that the large amounts of land in the categories of extra-narrow with dual access and small narrow with single access represent clear constraints on intensification.

\section{DENSITY}

We now want to turn to the density of development that has been occurring along these transit lines and how it is related to the morphology. The question of what is considered high, medium or low density will 
differ from one city and urban context to another - our framework is derived from this particular context. The net density in terms of dwellings/hectare was calculated for all intensified sites and also analysed for its relationship to lot size, shape and type of access. This measure of density was limited by the available data and does not account for average size of dwellings nor for the mix of retail space at ground level. The few new developments that were not primarily residential were not included in the analysis. The relationship between density and height was also explored. Figure 7 shows this data in graphic form.

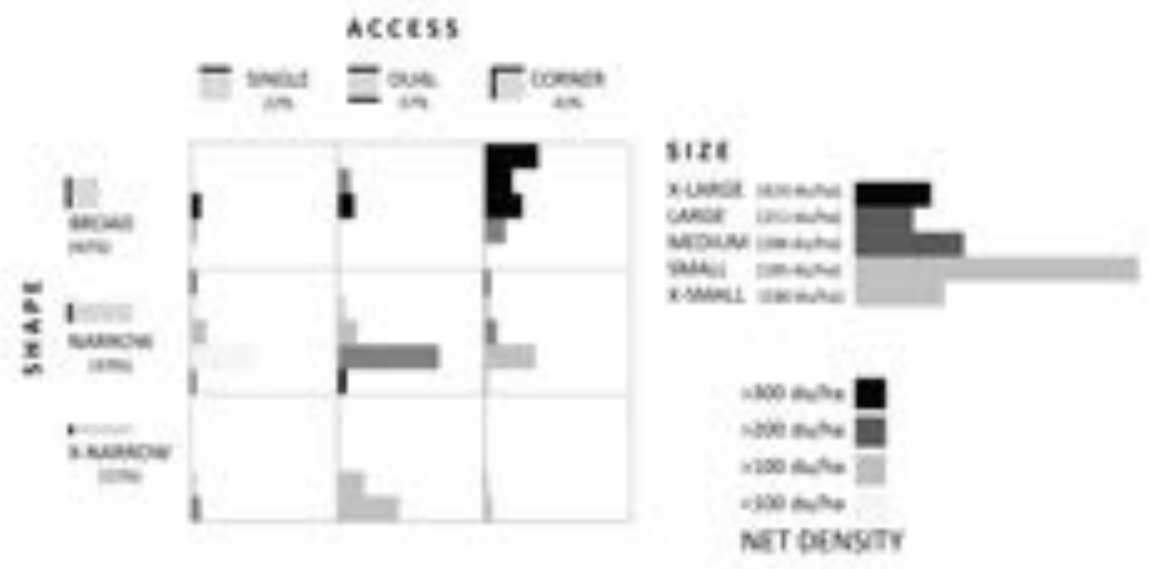

Figure 7: Density Yields by Access, Shape and Size.

The graph on size (Figure 7 - top right) shows that average densities in each lot size range from 180 to 424 dwellings/hectare and peak in the extra-large range. It is notable that the average densities achieved on small lots (185 du/ha) are only marginally increased on large blocks that can be up to 20 times larger. In other words there is a kind of density ceiling that is only exceeded on extra-large sites. This is partly an effect of larger blocks being re-developed at low densities further from the city, but also the effect of planning constraints and resident resistance to higher density development. Shape also had a significant relationship to density. The average density of broad blocks was more than double the average density of very narrow blocks, and notably higher than narrow blocks. This is consistent with the market preference for broad blocks, despite the limited occurrence of these along tram corridors. In terms of access the graph indicates that corner and dual access blocks yield notably higher levels of net density. Sites with single access produced an average of 135 dwellings/ha, while corner and dual access sites produced 222 and 245 dwellings/ha respectively. It is also the case that within the limited sample of developments, there was some evidence that more recent developments on small and narrow lots were achieving much higher densities due to changes in the market. During the last 15 years in Melbourne, apartments have become much smaller overall, with a greater number of 1-bedroom units and designs that utilize borrowed light.

\section{DISCUSSION}

We conclude this paper with a brief summary of key findings about morphological constraints of lot size, shape and access on processes of urban intensification. We also want to open up some larger questions about what is at stake here. What are the distinctions between urban 'intensification' and simple 'densification', and how is this impacted by lot size? What are the relations of small-lot morphologies to car-dependency? What does it mean to say that a particular urban neighbourhood has a particular development 'capacity'? We conclude that incremental intensification of small lot morphologies can make a substantial contribution to compact city policy, but this must be understood as part of a complex set of issues including density, demand, design and resident resistance. While many of the findings here are particular to Melbourne, we suggest that this study has significance for understanding the intensification of any small-lot morphology. The morphology of a mixed-use main street comprised of small-lots and a residential hinterland recurs globally with minor variations. Light rail or bus transit can be added to any 
street of more than about 20 metres width to enhance intensification capacity.

The key findings of this study involve the ways in which the size, shape and access conditions of small-lot morphologies can enable and constrain the intensification of transit corridors. Most of the intensification in this case is occurring on middle-sized lots with both extra-large and extra-small lots seeming to constrain development. Smaller lots have a lower yield and therefore lower profits often as a result of difficulties of access and narrowness of block shape. Very narrow sites were also identified as a significant constraint for intensification, producing the lowest average density of any site type. This validates the exclusion of very narrow sites from studies of intensification capacity (Adams 2009; Myers and Baird 1978). Broad sites were clearly attractive for intensification, allowing for greater flexibility in design, and yielding substantially higher densities. Corner access sites are also attractive - they possess better street views and natural light, and they often accrue symbolic capital due to enhanced visibility. Corner blocks have a more extensive public/private interface enabling better car access and increased profitability. These insights are broadly consistent with the existing literature, albeit in greater detail than previous studies. Most research to date has looked at the relationship between morphology and land values, or broad constraints to intensification; there has been little attention paid to the relationship between intensification itself and morphology. The method presented here is transferable, and provides a means of evaluating the patterns of intensification that occur in any given urban area.

The aversion to extra-large blocks is more complex to explain and our thoughts here are speculative. A large-scale development often requires a more substantial demand than currently exists in these suburban locations. There is a risk of lengthy delays in planning approval as planning amendments may be required. 'As-of-right' urban design and planning frameworks are more easily administered for small lots. Large projects are more likely to meet resident resistance and a risk of rejection by planning authorities (Woodcock et al. 2011). A limited number of developers are able to fund large projects and there can be higher levels of investment risk. The increased planning complexity increases the holding times and costs for site development - urban planning on large sites often becomes a new ball game.

Intensity and density

Public debate around urban intensification often becomes polarized into viewpoints that might be described as the 'density-is-necessary' lobby versus the 'density-destroys-character' lobby. Incremental intensification can be understood as a middle ground; the constraints that a small-lot morphology places on the speed, scope and forms of densification can be seen as positive for the city. Urban character becomes intensified rather than damaged; a greater diversity of developers and architects are involved; individual decisions have less consequence and can be made more quickly through as-of-right planning controls; the risks to amenity, character and community life are commensurate with the scale of the increments. Here we return to the connections between small-grain development and urban vitality first established by Jacobs (1961) and reiterated by Moudon (1986: 141) and others. Jacobs was also a key proponent of density and she famously suggested a minimum net density of about 250 dwellings/hectare. This is roughly the average density being achieved along these corridors and even the small and extra-small lots are not far below this figure (Figure 7). It is important to note that density is no simple measure; while it can be reduced to dwellings/hectare (as we have done) it is also variously measured in terms of population, jobs and floorspace, or misunderstood as simply building height (Dovey and Pafka 2014). While the words 'intensification' and 'densification' are often used synonymously, intensification also carries connotations of a mix of differences that are productive of intensive streetlife, character and urban buzz (Storper and Venables 2004). Urban intensity can be understood as a synergy of density, functional mix and access networks. When re-development of small-lot tramline corridors is done well then this is the outcome: light rail gives access, small lots ensure the mix and (as we suggest above) also hold the capacity for significant density.

\section{Car-dependency}

The suburbs of car-dependent cities such as the one we have studied cannot be successfully intensified without serious attention to questions of car access which clearly produces a loss of yield and compromised design outcomes on very narrow sites. Planning statutes within our study areas currently require at least one off-street parking space per new dwelling but such frameworks are in a state of transition and the market for apartments without parking is now a well-proven global trend (Glotz-Richter 1995; Manville 2013). If this trend continues the preference for narrow and single access sites will likely 
increase, as will both the affordability and the yield on those sites. On the other hand a common form of development along these corridors is where a single suburban house is replaced by multi-unit housing with car access dominating the street. This is a form of intensification that cuts across any prospect for a walkable mixed-use urban frontage at ground level - it can produce density without intensity. The best forms of development will include retail, commercial, community and production functions at ground level with a high quality pedestrian interface (Dovey and Wood 2015). This has implications for car access and there is a strong case to prohibit off-street parking on many small-lot development sites unless rear or side access is available. A transit corridor with a small-lot morphology inherently constructs a functional mix that works in synergy with good public public transport access and a walkable hinterland. While reduced car-dependency is a central goal of most intensification strategies, off-street parking remains an assumed premise of most new development.

\section{Capacity/Resistance}

Using the existing average net densities from our study, we are able to project broad estimates regarding the overall potential for intensification that exists along these corridors. This projected capacity is calculated by multiplying the average density for each site type to all existing sites. If all sites were intensified along these 6 tram corridors, we find that up to 45,000 dwelling units could potentially be produced. In other words, while about 2,500 dwellings have been added along these corridors during the study period, this could be increased about 18 fold before capacity is reached - based on current market practices - and this represents only $12 \%$ of all metropolitan tram corridors, suggestive of a total capacity for 360,000 dwellings. Although it is unrealistic to expect that every lot be redeveloped, the capacity that exists here suggests that incremental intensification presents a significant opportunity for absorbing growth and reducing car-dependency.

This concept of development capacity, however, is not so easily defined by the existing morphology and market preferences. If we deconstruct the concept of 'capacity' we find that it is both complex and elastic. Development capacity limits can be established by a mix of public transport capacity, morphological capacity, the need to balance heritage, character and amenity against density, and the political capacity to manage change in a democratic context. While it is well understood that capacity can be enlarged by public transport investment, it is not often recognized that creative urban design frameworks and effective community consultation can also have significant impact (Davison 2011). Melbourne has witnessed several resident and trader campaigns against tram corridor intensification and upgrading in the last decade; changing capacity requires high-quality community engagement and/or a high level of political nerve. Judgements about capacity are often political - the degree to which suburban neighbours will tolerate the loss of privacy and solar access that comes with higher buildings in close proximity.

Issues of perceived 'overdevelopment' emerge on both the front and rear interfaces of these transit strips. On the main frontage the key issue is the degree to which the street section is transformed and becomes seen as a 'canyon' where winter sunshine on public space is eroded. In Melbourne this is generally seen as between 4-6 storeys along the 20 metre-wide corridors through which most tram routes pass, and is often ameliorated by the use of setbacks above the 3rd or 4th floor (Woodcock et al. 2012). The rear interface with suburban housing can be the site of most conflict between neighbours and developers due to a loss of solar access and privacy. Here again, built form is often mediated with progressive setbacks to reduce the impact. The effect of these forces is often a building type that steps back on both front and rear interfaces to form a rough ridge. What is called for here is the design of new semi-urban building types that mediate between urban and suburban morphologies. What is understood as 'capacity' is then a compromise between suburban and urban densities.

The future of small-lot transit corridors of the kind we have studied here is by no means clear. They could easily be over-developed to the point where it makes little sense to retain the small-lot morphology. The practice of site amalgamation has not been studied here but if it proliferates then it could initiate a regime change and the capacity would then be dictated by the market. On the other hand existing densities could be preserved by policies that force new housing out to the urban fringe - in other words more of the same. Incremental intensification is the middle road. It relies on smart urban design codes, high quality design and genuine community engagement, but the accumulated effects of such incremental change can be significant. The capacity for change is not just change to urban form but also the 
incremental change in the attitudes of residents and traders as they realize the benefits of walkable access to frequent public transport and the rich mix of amenities that are possible along these corridors.

\section{REFERENCES}

Adams, R., 2009. Transforming Australian cities. The Australian economic review, 42 (2), 209-216. Berghauser Pont, M. and Haupt, P., 2010. Space matrix. Rotterdam: NAl.

Buxton, M. and Tieman, G., 2005. Patterns of urban consolidation in Melbourne. Urban policy and research, $23(2), 137-157$.

Cervero, R. and Kockelman, K., 1997. Travel demand and the 3Ds: Density, diversity, and design. Transportation research part D, 2 (3), 199-219.

Colwell, P. and Scheu, T., 1989. Optimal lot size and configuration. J. of urban economics, 26, 90-109.

Curtis, C., Renne, J. and Bertolini, L., eds. 2009. Transit Oriented Development. Farnham: Ashgate.

Davison, G., 2011. An unlikely urban symbiosis. Urban policy and research, 29 (2), 105-124.

Dovey, K., 2013. Planning and place identity. In: G. Young and D. Stevenson, eds, The Ashgate research companion to planning and culture, London: Ashgate, 257-271.

Dovey, K., 2016. Urban design thinking: A conceptual toolkit. London: Bloomsbury.

Dovey, K., Woodcock, I. and Wood, S., 2009. A test of character. Urban studies, 46 (1/2), 2595-2615.

Dovey, K. and Pafka, E., 2014. The urban density assemblage. Urban design international, 19 (1), 66-76.

Dovey, K. and Wood, S., 2015. Public/private urban interfaces. J. of Urbanism, 8 (1), 1-16.

Dittmar, H. and Ohland, G., 2004. The New Transit Town. Washington: Island Press.

Duany, A. and Talen, E., 2002. Transect planning. J. of the American planning association, 68 (3), 245266.

Dunham-Jones, E., and Williamson, J., 2011. Retrofitting Suburbia. Hoboken: Wiley.

Forsyth, A., 2015. What is a walkable place? Urban design international, 20 (4), 274-292.

Gao, X. and Asami, Y., 2007. Influence of lot size and shape on redevelopment projects. Land use policy, 24, 1, 212-222.

Glackin, S. and Trubka, R., 2013. Creating a spatial decision support system for housing redevelopment in Australian greyfields. $7^{\text {th }}$ Australasian housing researchers' conference proceedings. Fremantle, Australia.

Glotz-Richter, M., 1995. Living without a car. World transport policy and practice, 1 (1) 45-47.

Jacobs, J., 1961. The death and life of great American cities, New York: Random House.

Lewis, M., 2000. Suburban backlash. Melbourne: Blooming Books.

Lo, R., 2009. Walkability: what is it? J. of urbanism, 2 (2), 145-166.

Manville, M. 2013. Parking requirements and housing development. J. of the American planning association, 79 (1), 49-66.

March, A., Rijal, Y., Wilkinson, S. and Firidin, Ö., 2012. Measuring building adaptability and street vitality. Planning practice and research, 27(5), 531-552.

Marshall, S., 2009. Cities, design and evolution. London: Routledge.

Mejias, L. and Deakin, E., 2005. Redevelopment and revitalization along urban arterials. Transportation research record, 1902, 26-34

Moudon, A., 1986. Built for change. Cambridge, Ma.: MIT Press.

Myers, B. and Baird, G., 1978. Vacant lottery. Design quarterly, 108, Walker Art Centre, Minneapolis.

Newman, P., Beatley, T. and Boyer, H., 2009. Resilient cities. Washington: Island Press.

Newton, P., Newman, P., Glackin, S. and Trubka, R., 2012. Greening the greyfields, Int. J. social, behavioral, educational, economic, business and industrial engineering, 6 (11) 2870-89.

Newton, P. and Glackin, S., 2014. Understanding infill. Urban policy and research, 32 (2), 121-143.

Storper, M., and Venables, A., 2004. Buzz: face-to-face contact and the urban economy. J. of economic geography, 4(4), 351-370.

Tabuchi, T., 1996. Quantity premia in real property markets. Land economics, 72 (2), 206-217.

Talen, E., 2006. Design that enables diversity. J. of planning literature. 20 (3) 233-249.

Woodcock, I., Dovey, K., Wollan, S. and Beyerle, A., 2010. Modelling the compact city, Australian planner, 47 (2), 94-104.

Woodcock, I., Dovey, K. Wollan, S. and Robertson, I., 2011. Speculation and resistance. Urban policy and research, 29 (4): 343-362. 
Woodcock, I., Dovey, K. and Davison, G., 2012. Envisioning the compact city. Australian planner, 49 (1), 65-78.

Acknowledgements:

We thank Elek Pafka for his critique of an early draft of this paper and assistance with the diagrams. This work was supported by the Australian Research Council under Grant LP 100200590 